\title{
Christopher W. Thompson, Walking and the French Romantics. Rousseau to Sand and Hugo
}

\section{Michel Arrous}

\section{(2) OpenEdition}

1 Journals

\section{Édition électronique}

URL : https://journals.openedition.org/studifrancesi/45929

DOI : 10.4000/studifrancesi.45929

ISSN : 2421-5856

Éditeur

Rosenberg \& Sellier

\section{Édition imprimée}

Date de publication : 1 octobre 2007

Pagination : 451-452

ISSN : 0039-2944

\section{Référence électronique}

Michel Arrous, « Christopher W. Thompson, Walking and the French Romantics. Rousseau to Sand and Hugo ", Studi Francesi [En ligne], 152 (LI | II) | 2007, mis en ligne le 30 novembre 2015, consulté le 24 novembre 2021. URL : http://journals.openedition.org/studifrancesi/45929 ; DOI : https://doi.org/ 10.4000/studifrancesi.45929

Ce document a été généré automatiquement le 24 novembre 2021.

\section{(c) 9 (i) $\Theta$}

Studi Francesi è distribuita con Licenza Creative Commons Attribuzione - Non commerciale - Non opere derivate 4.0 Internazionale. 


\title{
Christopher W. Thompson, Walking and the French Romantics. Rousseau to Sand and Hugo
}

\author{
Michel Arrous
}

\section{RÉFÉRENCE}

CHRISTOPHER W. THOMPSON, Walking and the French Romantics. Rousseau to Sand and Hugo, Bern, Peter Lang, 2003, pp. 160.

1 Les romantiques français avaient-ils le sens de la marche et peut-on voir en eux les précurseurs de Jacques Lacarrière et de Jacques Réda? Dans ce petit livre plein d'allant Christopher W. Thompson s'est proposé d'analyser leur pratique de la marche. Sujet neuf que cette mode, inspirée de Rousseau, à laquelle s'adonnèrent bien sur les paysagistes, mais aussi et surtout des écrivains comme Nodier (dont Georges Zaragoza vient de rééditer la Promenade de Dieppe aux montagnes d'Écosse, Champion, 2003), Dumas, Hugo, Nerval, Sand et Flaubert. Mode qui eut du succès auprès des lecteurs comme en témoigne l'accueil des Impressions de voyage de Dumas et Le Rhin de Hugo. Si le célèbre agronome Arthur Young a pu juger les Français du xviii ${ }^{\mathrm{e}}$ siècle le peuple le plus sédentaire qui fût en Europe, tout a changé après 1800. Certes, Anglais, Suisses et Allemands s'étaient montrés plus hardis et il faudra attendre le premier quart du siècle pour que la «manie ambulante» de Rousseau et le goût des excursions alpestres de Senancour deviennent une pratique habituelle, particulièrement chez Nodier qui, avec ses amis artistes, encouragea Hugo à s'élancer sur les chemins, en compagnie de Juliette Drouet et du graveur Célestin Nanteuil. À l'exception de Sainte-Beuve, tous les romantiques marchent; certains, tel Dumas, n'hésitant pas à abattre quarante kilomètres en un jour... Thompson consacre de belles pages qui fourmillent de précisions à Hugo, Lamartine, Gautier, Ch. Didier. 
2 Dans la seconde partie, Thompson concentre son attention sur la marche en tant qu'expérience créatrice, à partir de l'exemple de Töpfer et de ses Voyages en zigzag et Nouveaux voyages en zigzag (1844 et 1854). Dans les vingt pages réservées à Sand, à ses excursions dans les Alpes, les Pyrénées, en Italie et, bien sur, dans la «Vallée Noire» et autour de Gargilesse - sans compter les promenades imaginaires, par exemple dans Consuelo - on voit combien la marche a compté dans la vie de l'auteur des Lettres d'un voyageur et des Promenades autour d'un village et combien cette activité, pratiquée seule ou en compagnie, avec ses plaisirs (possession de la nature, «activité romanesque de la vie errante et isolée»), a nourri sa réflexion et sa création, parce qu'elle fut pour elle une «éducation ambulante». Sand, véritablement, incarne la figure de l'artiste bohémien. Quant à Nerval, être poète ou voyageur, c'est tout un. On connaît ses pérégrinations, son exploration du Valois, et ses Nuits d'octobre peuvent être considérées comme la meilleure illustration de la flânerie urbaine, le tout sous le signe de Rousseau; sans oublier Aurélia où la marche acquiert une fonction thérapeutique, «cherchant dans la marche et dans la fatigue l'engourdissement de la pensée...». Le goût de Hugo pour la promenade, qui se manifestera dès 1820, connaît son plein développement à partir de 1837 (Picardie, Belgique, Allemagne, Suisse); mais Hugo se préoccupe fort peu de la performance physique; ce qu'il recherche, c'est la liberté qu'il ne manque pas de célébrer, une liberté capricieuse transformant ses parcours en «une extravagante arabesque» qui n'est pas sans rapport avec son goût de la digression. Pour Hugo, le promeneur est comme le poète, c'est celui qui va au-delà. Le dernier chapitre est réservé à Rodolphe Töpfer et à ses randonnées dans les Alpes dont la dimension est à la fois réaliste et humoristique.

3 La marche n'ait pas été la passion prédominante des romantiques français - Anglais et Allemands marchent d'un bien meilleur pas; ils l'ont cependant vécue et ra- contée comme une alternative radicale à la vie urbaine. Une bibliographie choisie (pp. 145-155) démontre amplement que Thompson n'a pas négligé des récits quasiment oubliés ou peu connus: Genoude, Janin ou L'Art de se promener de Karl Gottlob Schelle, récemment traduit en français (Payot, 1996). 